\title{
ASSESSMENT OF GENOTOXIC POTENTIAL OF HYDROGEN CYANAMIDE USING CHROMOSOMAL ABERRATION AND MICRONUCLEUS ASSAYS IN RAT BONE MARROW
}

\author{
Ahmad A. El-Ebiary*, Arwa A. Abuelfadl*and Naglaa I. Sarhan** \\ Departments of Forensic Medicine and Clinical Toxicology* and Histology**, Faculty of \\ Medicine, Tanta University
}

\begin{abstract}
Despite its widespread use in agriculture, data about cyanamide-induced genotoxicity are scanty, and its genotoxic potential was considered equivocal in vitro. Hence, the current study was carried out to evaluate the in vivo genotoxic potential of hydrogen cyanamide to complement the earlier in vitro research work. Thirty adult male rats were randomly assigned into 3 equal groups. Group I rats served as a control. Animals of groups II and III received hydrogen cyanamide in a dose of 10 and $20 \mathrm{mg} / \mathrm{kg}$ body weight/day respectively. All animals were treated by oral gavage, once daily, for 28 days. As end points, chromosomal aberrations, micronucleated polychromatic erythrocytes, mitotic index and polychromatic/normochromatic cell ratio in the animals' bone marrow cells were analyzed. Negative results were obtained regarding the presence of chromosome aberrations and micronuclei in each of the lowdose and high-dose cyanamide-treated rats compared to the controls. Also, cyanamide treatment did not reduce the mitotic index or polychromatic/normochromatic cell ratio in the exposed animals. This study found that hydrogen cyanamide exposure had no genotoxic potential in rat bone marrow cells in the doses used and under the conditions of the performed assays.
\end{abstract}

Key words: hydrogen cyanamide; genotoxicity; chromosome aberration; micronucleus assay.

\section{INTRODUCTION}

Hydrogen cyanamide was patented as a plant growth regulator used to induce chemical vernalization and uniform bud break from dormancy (Schep et al., 2009). Despite its widespread use in agriculture, the effects of human exposure to cyanamide have not been sufficiently studied (Davanzo et al., 2001; Settimi et al., 2007).

Safety standards consider the product as highly toxic with rat oral $\mathrm{LD}_{50}$ of $125 \mathrm{mg} / \mathrm{kg}$ (Lewis and Sax, 2004). In laboratory animals cyanamide induces adverse effects in the liver, thyroid, kidneys, ovaries and testes, and it has the potential to cause similar effects in humans. These adverse effects were identified in sub-chronic toxicity, chronic toxicity and oncogenicity studies (Grant, 1986; Proctor et al., 1996; Sheshadri et al., 2011).

Human acute cyanamide exposure has been associated with dizziness, nausea, vomiting, heartburn, dyspnea, tachycardia and severe irritation and ulceration of the skin, conjunctiva and respiratory tract mucosa (Davanzo et al., 2001; Settimi et al., 2007; Sheshadri et al., 2011). In alcohol abusers it can produce disulfiram-like syndrome, characterized by confusion, 
parasympathetic hyperactivity, vomiting, dyspnea, hypotension and tachycardia, due to inhibition of aldehyde dehydrogenase enzyme (de Haro, 2009; Lorenzo de la Pena et al., 2006; Proctor et al., 1996).

Preliminary in vitro (stage 1) studies on the genotoxic potential of cyanamide reported that it did not stimulate unscheduled DNA synthesis and was not mutagenic in Ames test (Cadena et al., 1984). To develop weight of evidence the genotoxicity testing should include in vivo (stage 2) tests to provide detailed information of biological and physiological significance. Some agents are mutagenic in vivo but not in vitro, and so it is prudent to include assays that account for toxicokinetic aspects (absorption, distribution, metabolism and excretion), which are not factors in the in vitro tests but are potentially relevant to human use (Hsu and Wang, 2015).

Chromosomal aberrations (CA) test, being the most sensitive genotoxicity end point, is one of the best techniques to evaluate genetic damage although it is labor intensive. On the other hand micronucleus (MN) assay is a highly reliable, fast, screening technique that can detect a range of clastogens and aneugens. However, no single biological marker can be considered a good indicator of exposure to hazardous xenobiotics or a good predictor of adverse health effects, and only after inclusion of appropriate in vivo assays absence of significant genotoxic risk can be demonstrated (Albertini et al., 2000; Baker and Connor, 1996; Bonassi et al., 2007; Jenssen and Ramel, 1980). Hence, the current study was carried out using both the sensitive CA technique and the $\mathrm{MN}$ assay for evaluation of genome damage induced by hydrogen cyanamide in the rat bone marrow cells to complement the earlier in vitro genotoxicity research work.

\section{MATERIALS \& METHODS}

\section{Chemicals:}

Hydrogen cyanamide was purchased from a local commercial source. All other chemicals used in the study were of the highest purity available, and were obtained from ElNasr, Pharmaceutical Chemicals Company (Cairo, Egypt).

Compliance with ethical standards:

The Research Ethics Committee of Tanta Faculty of Medicine approved the study protocol. The current study was carried out on 30 adult male albino rats with average body weight of $200 \pm 20 \mathrm{gm}$. They were housed in clean, properly ventilated cages (five rats in each cage), under standard environmental conditions of lighting (12 $\mathrm{h}$ light/dark cycles) and temperature $\left(23 \pm 2{ }^{\circ} \mathrm{C}\right)$, with free access to food and water throughout the experiment. They were acclimatized to their environment two weeks before starting the experiment.

\section{Experimental design:}

The animals were randomly assigned into 3 groups (10 rats each). Group I animals served as a control. Animals of groups II (low-dose group) and III (high-dose group) received hydrogen cyanamide in a dose of 10 and $20 \mathrm{mg} / \mathrm{kg}$ body weight/day respectively. Hydrogen cyanamide was dissolved in sterile distilled water. Control animals received equivalent amounts of the vehicle. All animals were treated by oral gavage, once daily, for 28 days. The animals were examined for clinical manifestations of toxicity throughout the study. At the 
end of the treatment period, the rats were sacrificed 24 hours after the last dosing, dissected, their femurs removed and the bone marrow extracted.

\section{Chromosomal aberration assay:}

The animals were intraperitoneally injected with $4 \mathrm{mg} / \mathrm{kg}$ body weight colchicine $1 \mathrm{~h}$ prior to sacrifice to arrest the cells at metaphase. The bone marrow from each of these animals was eluted in $5 \mathrm{~mL}$ Hanks' Solution and centrifuged at $1000 \mathrm{rpm}$ for $5 \mathrm{~min}$. The pellets were suspended in $10 \mathrm{ml}$ aqueous $\mathrm{KCl}(0.075 \mathrm{M})$ and incubated for $12 \mathrm{~min}$ at $37{ }^{\circ} \mathrm{C}$. The cells were fixed in glacial acetic acid/methanol solution $(1: 3, \mathrm{v} / \mathrm{v})$, centrifuged, washed 3 times and suspended in a small volume of the fixative. The fixed cells were smeared onto clean glass slides and air-dried. Slides were washed 3 times with purified water, stained with Giemsa for $15 \mathrm{~min}$, rinsed, air-dried and mounted with cover slips. The slides were coded before analysis in a blind manner. Metaphases containing between 40 and 44 chromosomes were accepted for scoring. For each animal, a total of 100 well-spread metaphases were screened for CA. The mitotic index (percentage of cells in mitosis) was scored in 1000 cells per animal as an indicator of cytotoxic activity (Kirkland et al., 2015).

\section{Micronucleus assay:}

The marrow flushed out from the bones was collected with $3 \mathrm{ml}$ of fetal bovine serum and centrifuged at $1000 \mathrm{rpm}$ for $5 \mathrm{~min}$. The serum was discarded and the pellet was spread onto a clean glass slide and air-dried. The slides were stained with Giemsa, mounted with cover slips and coded before analysis in a blind manner. For each animal, a total of 2000 polychromatic erythrocytes (PCE) were analyzed for the frequency of micronuclei. Toxicity to bone marrow was assessed by scoring a total of 1000 erythrocytes per animal to determine the ratio of $\mathrm{PCE}$ to normochromatic erythrocytes (NCE) (Kirkland et al., 2015).

\section{Statistical analysis:}

Statistical analysis was performed using the Statistical Package for Social Sciences for Windows (SPSS Inc., Chicago, IL, USA, Version 16.0). The results were recorded as mean and standard deviation for each group, and then the differences between the treated groups and the controls were statistically evaluated using one-way analysis of variance (ANOVA) test. $p \leq 0.05$ was considered statistically significant.

\section{RESULTS}

No mortalities occurred in the control or the cyanamide-treated groups, and all animals remained healthy until the harvest timepoint. Aberrations in the form of gaps, breaks, fragments and dicentric chromosomes were evident (Figs. 1-3). The frequencies of aberrant cells in any of the cyanamide-treated groups were not significantly different from that of the control group. The frequencies of micronucleated PCE from both the low-dose and high-dose cyanamidetreated animals did not differ significantly from that observed in the control group. Also, animal treatment with 10 and $20 \mathrm{mg} / \mathrm{kg}$ body weight/day cyanamide was not cytotoxic to the bone marrow, since it had no significant effect on mitotic index and did not significantly reduce the PCE:NCE ratio in exposed animals compared to their respective controls (Table 1). 


\begin{tabular}{|l|l|}
\hline Figure (1): A photomicrograph of a \\
metaphase spread of rat bone marrow \\
cells of group I showing normal \\
chromosomal structure. (Giemsa \\
stain) (Mic. Mag., $\mathrm{X}$ 1000)
\end{tabular}


Table (1): ANOVA test comparison of the rat bone marrow chromosome aberrations, mitotic index and micronuclei data for the control and the cyanamide-treated groups.

\begin{tabular}{|c|c|c|c|}
\hline & $\begin{array}{l}\text { Group I } \\
\text { (Control) }\end{array}$ & $\begin{array}{l}\text { Group II } \\
\text { (Low -dose } \\
\text { cyanamide) }\end{array}$ & $\begin{array}{l}\text { Group III } \\
\text { (High - dose } \\
\text { cyanamide) }\end{array}$ \\
\hline Number of animals & 5 & 5 & 5 \\
\hline Total metaphases scored $^{\mathrm{a}}$ & 500 & 500 & 500 \\
\hline Cells with structural CA (group mean $\pm \mathrm{SD})^{\mathrm{b}}$ & $1.4 \pm 0.55$ & $1.2 \pm 0.84$ & $1.6 \pm 0.55$ \\
\hline Gaps $(\%)$ & 1.0 & 0.8 & 1.2 \\
\hline Breaks (\%) & 0.4 & 0.4 & 0.2 \\
\hline Fragments $(\%)$ & 0.2 & 0.6 & 0.4 \\
\hline Dicentric chromosomes (\%) & - & - & 0.2 \\
\hline Mitotic index (group mean \pm SD) & $11.02 \pm 1.08$ & $10.32 \pm 1.55$ & $10.48 \pm 1.43$ \\
\hline $\mathrm{MN} / 1000 \mathrm{PCE}^{\mathrm{c}}$ (group mean $\left.\pm \mathrm{SD}\right)$ & $2.00 \pm 0.61$ & $2.20 \pm 1.15$ & $2.30 \pm 1.20$ \\
\hline$\% \mathrm{PCE}^{\mathrm{d}}($ group mean $\pm \mathrm{SD})$ & $55.04 \pm 5.04$ & $54.68 \pm 4.42$ & $54.08 \pm 4.42$ \\
\hline
\end{tabular}

CA: chromosomal aberration; SD: standard deviation; MN: micronuclei; PCE: polychromatic erythrocyte.

${ }^{a}$ For each animal 100 cells were analyzed, to a total of 500 metaphase cells per group.

${ }^{b}$ Some metaphases had more than one aberration.

${ }^{c} A$ total of 2000 PCE per animal were scored.

${ }^{\mathrm{d} A}$ total of 1000 erythrocytes per animal were scored.

\section{DISCUSSION}

Hydrogen cyanamide is an active ingredient, which was patented as a plant growth regulator. It was not mutagenic in Ames assay, and it did not stimulate unscheduled DNA synthesis in vitro (Cadena et al., 1984; Schep et al., 2009). However, it induced CA in Chinese hamster cells in vitro (Ivett 1987, unpublished study). Hence, the current study was conducted to evaluate the in vivo genotoxic potential of hydrogen cyanamide using the sensitive CA technique in addition to the MN assay, which enables both chromosome breakage and loss to be measured reliably.

Actual exposure conditions take place either during cyanamide production or application to plants or during consumption of cyanamidecontaminated products. These conditions arise from exposure to small doses for long period. Therefore, in a trial to simulate actual exposure conditions for consumers of cyanamide-contaminated products, relatively small doses (10 and 20 $\mathrm{mg} / \mathrm{kg}$ body weight/day) were used via the oral route for longer duration of exposure. Such difference in both dose and duration make this work rational as well as other comparable studies (Menargues et al., 1984).

The present study found no significant increase in the frequencies of aberrant cells or micronucleated PCE in cyanamide-treated animals compared to their respective controls. Animals treated with cyanamide did not show significant changes in mitotic index or the PCE:NCE ratio, reflecting the absence of cytotoxic effect on the bone marrow. These results indicate that under the exposure conditions evaluated and for the calculated power of the study, cyanamide exposure did not result in a significant increase in genome damage in the cell population 
evaluated. It has been reported that the frequency of DNA damage may decrease with increasing time between exposure and sampling, which could be explained in light of the continued DNA repair processes and loss of seriously damaged cells through apoptosis. Therefore, in the current study the samples were collected 24 hours after exposure termination. This has been considered as the optimal sampling time during a long-term exposure because induction and repair of DNA damage is supposed to be at steady state (Albertini et al., 2000).

Genotoxicity testing on Swiss mice that received 2 doses of cyanamide at intervals of 24 hours revealed no deviation in MN counts in polychromatic cells of cyanamidetreated animals compared to their control (Menargues et al., 1984). In another study, cyanamide administration to mice once orally in a dose of $31.4,157.4$ and $330.5 \mathrm{mg} / \mathrm{kg}$ did not lead to any significant increase in the $\mathrm{MN}$ rate in polychromatic erythrocytes, and cyanamide was thus considered as negative under the test conditions of this assay (SKW, 1987, unpublished study). In accordance with these reports, smaller doses and longer period of hydrogen cyanamide exposure in the present study did not show significant differences in $\mathrm{MN}$ frequency between control and exposed animals. According to the best of our knowledge, no research work has observed the presence of CA in cyanamide-treated rats. Hence, it was prudent to include CA assay for evaluation of genotoxic potential of hydrogen cyanamide because of its presumed higher sensitivity (Klisesch et al. 1981), in addition to the presence of experimental and epidemiological evidence for the association of increased CA frequency with an increased overall risk for cancer (Bonassi et al., 2008).

\section{CONCLUSIONS}

Evaluation of DNA damage using different genotoxicity testing techniques has been considered as an essential step to understand carcinogenesis and assess the risk of cancer incidence. The results obtained in this study, as well as scanty studies by other authors, point to lack of clastogenic and aneugenic activity of hydrogen cyanamide under the conditions of these assays. However, research work using longer durations of exposure and different species of test animals, in addition to assessment of exposed individuals, taking into consideration the intensity, duration and pattern of exposure, are mandatory for comprehensive evaluation of cyanamide mutagenic potential.

\section{REFERENCES}

Albertini $\overline{\text { RJ, Anderson D, Douglas }}$ GR et al (2000): Ipcs guidelines for the monitoring of genotoxic effects of carcinogens in humans. International programme on chemical safety. Mutat Res 463:111-172.

Baker ES, Connor TH (1996): Monitoring occupational exposure to cancer chemotherapy drugs. American journal of health-system pharmacy : AJHP : official journal of the Am J Health Syst Pharm 53:2713-2723.

Bonassi S, Znaor A, Ceppi $M$ et al (2007): An increased micronucleus frequency in peripheral blood lymphocytes predicts the risk of cancer in humans. Carcinogenesis 28:625-631. 
Cadena A, Arso J, Vallès JM et al (1984): Evaluacion de la posible mutagenicidad de la cianamida mediante las pruebas de ames y devoret. Bollettino chimico farmaceutico 123:74-82.

Davanzo F, Travaglia A, Chiericozzi $M$ et al (2001): [pesticide poisoning referred to the poison center of milan in 1995-1998]. Ann Ist Super Sanita 37:127-131.

de Haro L (2009): Disulfiram-like syndrome after hydrogen cyanamide professional skin exposure: Two case reports in france. J Agromedicine 14:382384.

Bonassi S, Norppa H, Ceppi $M$ et al (2008): Chromosomal aberration frequency in lymphocytes predicts the risk of cancer: results from a pooled cohort study of 22358 subjects in 11 countries. Carcinogenesis 29:1178-1183.

Grant WM (1986): Toxicology of the eye : Effects on the eyes and visual system from chemicals, drugs, metals and minerals, plants, toxins and venoms : Also, systemic side effects from eye medications. Springfield:Charles C. Thomas.

Hsu C-H, Wang Q (2015): Genotoxicity testing strategies, guidelines, and methods.11731188.

Jenssen D, Ramel C (1980): The micronucleus test as part of a shortterm mutagenicity test program for the prediction of carcinogenicity evaluated by 143 agents tested. Mutat Res 75:191-202.

Kirkland D, Brock T, Haddouk $H$ et al (2015): New investigations into the genotoxicity of cobalt compounds and their impact on overall assessment of genotoxic risk. Regul Toxicol Pharmacol 73:311-338.

Klisesch U, Danford N, Adler ID (1981): Micronucleus test and bone-marrow chromosome analysis: a comparison of 2 methods in vivo for evaluating chemically induced chromosomal alterations. Mutat Res 80:321-332.

Lewis RJ, Sax NI (2004): Sax's dangerous properties of industrial materials. Hoboken, N.J.:J. Wiley \& Sons.

Lorenzo de la Pena L, Montero Santos JM, Benito Lozano $M$ et al (2006): [acetaldehyde syndrome after laboral exposition to hydrogen cyanamide]. Med Clin (Barc) 127:717-718.

Menargues A, Obach R, Valles JM (1984): An evaluation of the mutagenic potential of cyanamide using the micronucleus test. Mutat Res 136:127-129.

Proctor NH, Hughes JP, Hathaway GJ (1996): Proctor and hughes' chemical hazards of the workplace. New York:Van Nostrand Reinhold.

Schep L, Temple W, Beasley M (2009): The adverse effects of hydrogen cyanamide on human health: An evaluation of inquiries to the new zealand national poisons centre. Clin Toxicol (Phila) 47:5860.

Settimi L, Davanzo F, Travaglia A et al (2007): [italian program for surveillance of acute pesticiderelated illnesses: Cases identified in 2005]. G Ital Med Lav Ergon 29:264-266.

Sheshadri SH, Sudhir U, Kumar S et al (2011): Dormex-hydrogen cyanamide poisoning. J Emerg Trauma Shock 4:435-437. 


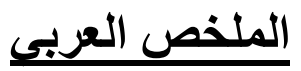

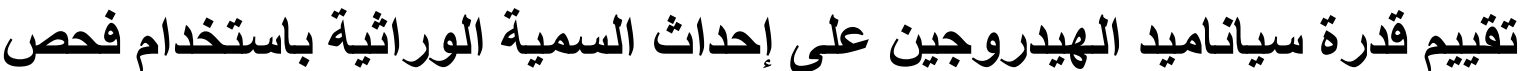

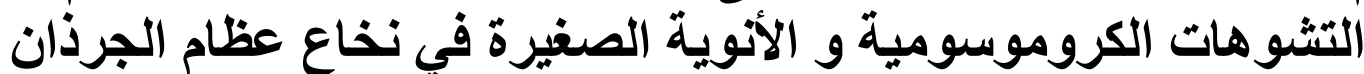

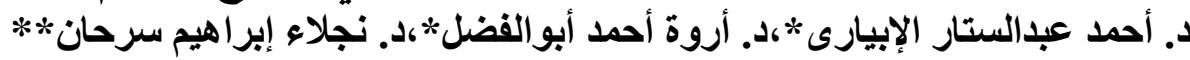

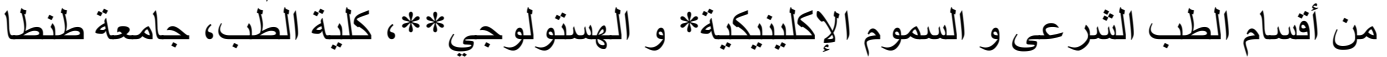

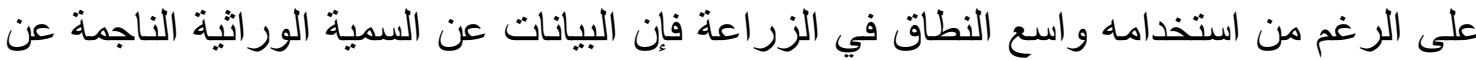

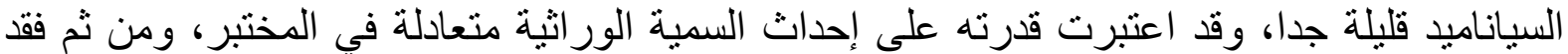

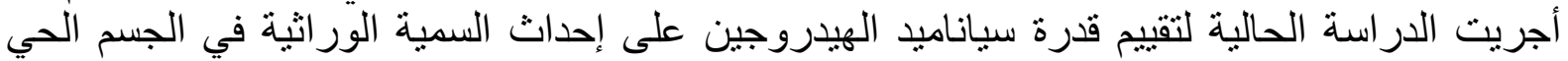

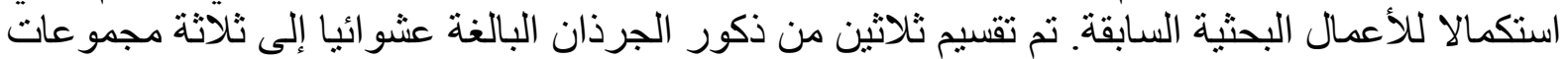

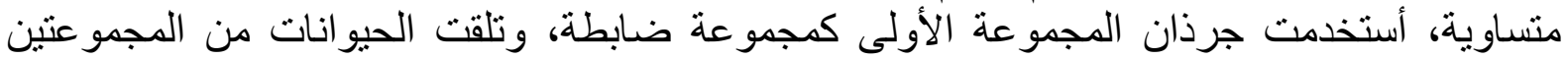

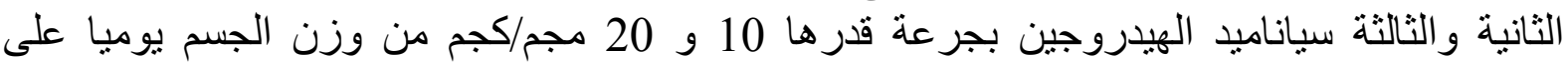

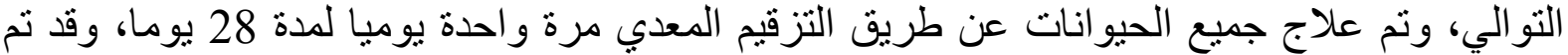

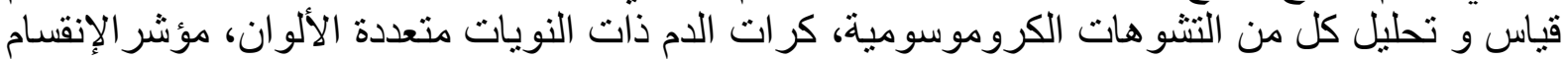

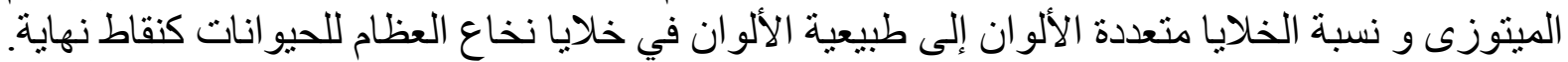

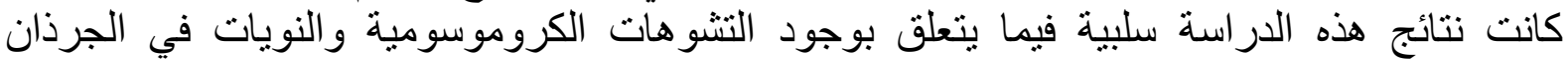

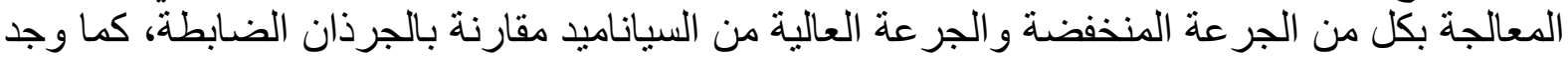

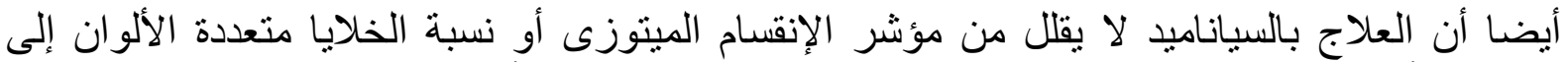

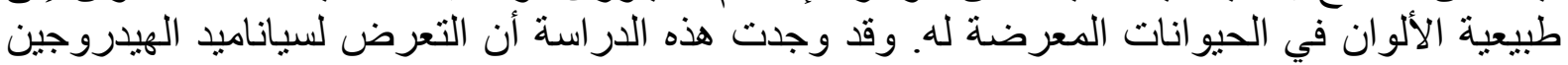

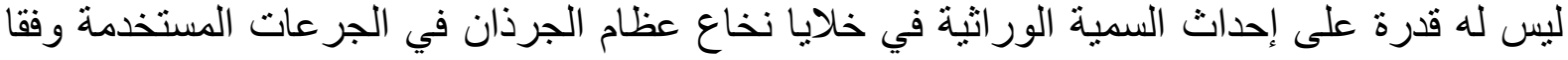
لشروط القياسات التي تم عملها. 